\title{
JUVENTUDES, EDUCAÇÃO E PROJETOS DE FUTURO: ESTUDO SOBRE ESTUDANTES COTISTAS NA EPTNM DA RFEPCT
}

\author{
Jose Geraldo Pedrosa*; Aldo Geraldo Simões. \\ *e-mail: jgpedrosa@uol.com.br \\ Centro Federal de Educação Tecnológica de Minas Gerais \\ DOI: 10.15628/rbept.2020.10237
}

Artigo submetido em: Maio/2020 e aceito em: Set/2020

\begin{abstract}
RESUMO
O artigo diz respeito a jovens com idade entre dezessete e dezenove anos, egressos do ensino fundamental público em escolas de periferia urbana, de baixa renda, autodeclarados pretos ou pardos, que ingressaram na EPTNM da RFEPCT pela lei de cotas. O objetivo é identificar a RFEPCT como campo de experiências e possibilidades para projetos de futuro. A referência teórico-metodológica articula campo de possibilidades e projetos (Velho) e experiência e horizonte de expectativas (Koselleck) num estudo de discursos sobre si próprios apurados em entrevistas focalizadas individuais. Os resultados permitem ler a precariedade da escola pública periférica de tempo parcial e também situar componentes da escola pública de boa qualidade como plataforma para projetos. Que as experiências na escola de tempo integral são abrangentes e incluem vivências e convivências diversas. Os resultados constatam que os cotistas têm, desde o ensino fundamental, uma trajetória marcada pelo mérito escolar e social.
\end{abstract}

Palavras-Chaves: Juventudes. Cotas escolares. Meritocracia. Campo de possibilidades. Projetos de futuro.

\section{YOUTHS, EDUCATION AND FUTURE PROJECTS: STUDY ABOUT QUOTA STUDENTS AT EPTNM DA RFEPCT}

\begin{abstract}
This article is about young people aged 17 to 19 years old, graduates of public elementary school in suburban schools, low- income, self-declared black or brown, who joined the EPTNM of RFEPCT by the law of quotas. The objective is to identify RFEPCT as a field of experiences and possibilities and for future projects. The theoretical-methodological reference articulates field of possibilities and projects (Velho) and experience and a variety of expectations (Koselleck) in a study of speeches about themselves determined in individual focused interviews. The results allow us to read the precariousness of the part-time peripheral public school and place good quality public school components as a platform for projects. The experiences in full-time school are extensive and include diverse experiences and coexistence. The results confirm that the quota students have, since Elementary School, a trajectory marked by school and social merit.
\end{abstract}

Key words: Youths. School quotas. Meritocracy. Field of possibilities. Future projects. 


\section{INTRODUÇÃO}

O assunto abordado neste artigo envolve jovens estudantes cotistas, pobres e vindos do ensino fundamental de escolas públicas de periferias urbanas que ingressaram na Educação Profissional e Técnica de Nível Médio (EPTNM) da Rede Federal de Educação Profissional, Científica e Tecnológica (RFEPCT), beneficiados pela Lei n. 12.711/2012 (Lei de Cotas). A questão que orientou a pesquisa considerou a EPTNM da RFEPCT como um campo de possibilidades e seus sujeitos cotistas como eventuais portadores de projetos de futuro. Nesse sentido a questão foi tanto a de identificar os elementos constitutivos desse campo de possibilidades na significação elaborada pelos jovens, quanto a de relacioná-los aos projetos desses jovens.

A referência teórica que inspirou a pesquisa e forneceu os termos do problema buscou articular a perspectiva antropológica de Gilberto Velho, e histórica de Reinhart Koselleck, com alguns flertes com as perspectivas sociológicas de Sennett e psicanalíticas de Freud. De Velho e Koselleck vieram respectivamente as noções de campo de possibilidades e projetos de futuro, e de espaço de experiência e horizonte de expectativas. De Sennett vieram as considerações a respeito da prevalência do curto prazo e da efemeridade típicos do tempo presente na corrosão do caráter. De Freud vieram as questões relativas à psique humana, à economia libidinal, aos desejos, enfim, às motivações e expectativas de satisfação daquilo que atua como causa e impele à ação, como as realizadas na elaboração de projetos.

Velho (2003, p. 40) define projeto como "(...) a conduta organizada para atingir finalidades específicas", isto é, a conduta organizada para atingir as condições necessárias à manutenção da vida que já se tem ou daquela com que se sonha e que se deseja alcançar. Nesse sentido, o projeto de futuro do estudante cotista se expressa na forma como ele se organiza e se prepara para viver a vida presente e futura. Projetar equivale, pois, a vislumbrar cenários futuros que demandem atitudes e condutas para alcançar finalidades específicas, que proporcionariam condições adequadas ao desenvolvimento do projeto de vida. Assim entendido, os sujeitos dependem de determinadas condições para que o projeto de futuro tanto se delineie quanto oriente condutas. Seguindo essa linha, a questão é saber quais são os projetos de futuro ou horizontes de expectativas de jovens estudantes da EPTNM atendidos pela política de cotas regulamentada pela Lei $n .^{\circ}$ 12.711/2012 e de que maneira esses projetos e horizontes estão relacionados às possibilidades e experiências vividas no ambiente da RFEPCT.

A pesquisa que deu origem ao presente artigo foi realizada numa unidade da RFEPCT situada numa cidade de porte médio em Minas Gerais. Os sujeitos da pesquisa foram os estudantes com idade entre dezessete e dezenove anos, matriculados no último ano da EPTNM na modalidade integrada em tempo integral. Essa definição considerou que a presença de quase três anos na ambiência da RFEPCT era tempo para um mergulho 
pessoal numa escola federal situada num campus equipado com infraestrutura de laboratórios e oficinas, cursos superiores e médios de tempo integral, com elevado percentual de professores com mestrado e doutorado e de estudantes regularmente bem avaliados no Exame Nacional do Ensino Médio (Enem). A definição do perfil dos sujeitos pesquisados também considerou que o terceiro ano, o ano de conclusão do curso técnico de nível médio, é um momento de encerramento de um ciclo pessoal. Momento carregado de simbolismos, marcado pela vida escolar na educação básica em condições de menoridade etária, pela passagem para o ensino superior ou o mercado de trabalho e para a maioridade etária. Ressalta-se ainda que os jovens em questão se diferenciam entre os demais por atender a todos os critérios postos na Lei 12.711/2012 para ter acesso à reserva de vagas: são egressos do ensino fundamental público, são de baixa renda e etnicamente autodeclarados pretos, pardos ou indígenas.

A pesquisa, realizada no ano de 2018, foi qualitativa e não permite generalizações. Ao longo de um semestre foram ouvidos nove, num universo de quinze sujeitos que atendiam a todos os critérios estabelecidos. A meta era ouvir os quinze sujeitos, mas, ao se chegar à nona entrevista, ficou evidente certa exaustão das respostas, demonstrada em reincidências.

Segundo Velho (1999, p.27), “(...) por mais precário que possa ser o método, é a verbalização, através de um discurso que pode fornecer as indicações mais precisas sobre projetos individuais". Por isso, para realização da pesquisa optou-se pela entrevista focalizada individual. Além de uma situação confortável para a conversa com os jovens - o contrário de um interrogatório -, privilegiou-se a verbalização por intermédio de um discurso espontâneo com perguntas abertas e focalizadas em três eixos: a) biografia e memória; b) experiências na EPTNM da RFEPCT como campo de possibilidades; e c) horizontes de expectativas e projetos de futuro. As entrevistas foram gravadas, transcritas e cada qual transformada num texto narrativo, estruturado conforme a ordem do roteiro no qual os sujeitos se tornaram personagens com nomes fictícios.

Os resultados não podem ser generalizados, mas constituem descobertas interessantes e inéditas para as discussões que envolvam jovens pobres, cotas escolares, equidade e meritocracia. Por um lado, eles permitem uma leitura das precárias condições da escola pública, periférica, de tempo parcial e frequentada por sujeitos pobres (que passam na rua a outra parte do tempo não ocupado pela escola). Em casa de pobre os pais geralmente passam o dia ocupados com o trabalho, condição esta que expõe os filhos às convivências e experiências do mundo da rua. Os sujeitos entrevistados têm um ponto de vista singular sobre a escola pública brasileira, pois, além de conhecê-la por dentro, puderam fazer comparações, possibilitadas pelo acesso à EPTNM da RFEPCT. Os resultados permitem também situar os elementos constitutivos da escola pública de boa qualidade como um campo de possibilidades ou plataforma para projetos de futuro. Em outros termos, as 
verbalizações dos estudantes cotistas sobre a ambiência da EPTNM da RFEPCT indicam que as experiências formativas na escola de tempo integral são bem mais abrangentes que a sala de aula e incluem a vivência de situações diversas e convivência com sujeitos também diversos. Por fim, os resultados permitem compreender os sujeitos cotistas: eles não são desprovidos de mérito escolar.

\section{COTAS ESCOLARES PÚBLICAS: DEFINIÇÕES E HISTÓRIA}

No universo das políticas de inclusão social, as cotas escolares públicas e a reserva de vagas a públicos estruturalmente desfavorecidos apresentamse como evento e campo para pesquisa em razão de sua recente normatização pelo Estado brasileiro e das controvérsias que a questão desperta tanto entre os especialistas quanto na opinião comum.

A inclusão é um processo de transferência pacífica e consensual, entre outras questões, de poder e oportunidades àqueles que se encontram involuntariamente em situação de vulnerabilidade, pobreza ou incapacidade, para que possam progressivamente superar tais condições (CARVALHO, 2016). Desse ponto de vista, políticas de inclusão social objetivam promover suportes, condições e acesso a outros espaços de experiências e campos de possibilidades, tendo em vista promoverem novos horizontes de expectativas e projetos de futuro para os seus contemplados.

De acordo com Bayma (2012, p. 329), "(...) as ações afirmativas são entendidas como ferramenta para busca de uma igualdade material, isto é, que considere o contexto social constituído, por exemplo, por grupos minoritários". São "(...) medidas [...] que visam promover a igualdade substancial, através da discriminação positiva de pessoas integrantes de grupos [...] situação desfavorável, e que sejam vítimas de discriminação e estigma social" (SARMENTO apud BAYMA, 2012, p. 328).

Na década de 1950 a Índia era o país com a mais longa experiência relacionada a políticas de ação afirmativa. Segundo Carvalho (2016, p. 17), "(...) o modelo de cotas indianas significou uma revolução profunda no modelo constitucional de corte ocidental e serviu de inspiração para políticas de inclusão equivalentes, tais como as ações afirmativas nos Estados Unidos, Malásia e África do Sul". Nos Estados Unidos da América (EUA), França e Espanha, existem expressões diferentes para tratar das políticas de inclusão. $\mathrm{Na}$ França, a expressão mais veiculada é a ação afirmativa, enquanto que nos EUA e na Espanha a expressão usual é a discriminação positiva. Esses países desenvolvem, a princípio, atividades com fins muito parecidos: promover a inclusão e afirmar as diferenças de grupos e minorias discriminadas.

Apesar da semelhança quanto às finalidades, as expressões não são utilizadas de modo aleatório. A despeito de serem conduzidas pelo Estado, 
caso as propostas de combate à desigualdade se originem daqueles que demandam, as cotas parecem identificar-se com o que almejam os proponentes da discriminação positiva, pois atendem ao que o próprio indivíduo define como condição para poder desenvolver-se. Caso partam daquele que as concede, as cotas parecem identificar-se com o que pretende a ação afirmativa, ou seja, dar suporte àquilo que o Estado entende ser necessário aos indivíduos para sua inclusão social.

Resguardadas as diferenças das origens das propostas de inclusão e de reequilíbrio na distribuição e participação social, é possível definir, a partir de Bayma (2012), Camino (2014) e Carvalho (2016), que as políticas afirmativas visam a corrigir desigualdades por meio de intervenções proporcionais aos efeitos negativos reconhecidos como fatores de restrição ao exercício da cidadania e/ou $\mathrm{o}$ acesso aos meios materiais necessários ao desenvolvimento do sujeito-cidadão, o que, por extensão, produz efeitos nos projetos de futuro.

A proposta de cotas na educação tem assento no reconhecimento da necessidade de promoção de condições de participação social de grupos minoritários que, em função das características que os diferenciam, sofrem com processos de exclusão e entraves no acesso a bens e serviços. Propostas de reservas de vagas escolares são recentes no Brasil e elas emanam de outras medidas como as de reserva de vagas de trabalho para mulheres, deficientes físicos ${ }^{1}$, negros ${ }^{2}$ em concursos públicos e para mulheres na política ${ }^{3}$.

Segundo Camino (2014), a formulação de políticas afirmativas remonta a:

(...) 1931 com a lei dos Dois Terços $^{4}$, quando as empresas, face a forte imigração europeia, foram obrigadas a destinar $2 / 3$ das suas vagas a trabalhadores brasileiros. A partir da década de 1990, diversas leis consolidam as ações afirmativas no Brasil, como exemplo: a destinação de $20 \%$ das vagas de serviço público para portadores de deficiência e $30 \%$ para mulheres. (CAMINO, 2014, p. 119.)

\footnotetext{
1 Lei 7.853/1989, regulamentada pelo Decreto 3.298/1999, e Lei 8.112/1990, que dispõem sobre a integração da "pessoa portadora de deficiência".

${ }^{2}$ Lei $12.990 / 2014$, reserva aos negros $20 \%$ das vagas oferecidas nos concursos públicos para provimento de cargos efetivos e empregos públicos no âmbito da administração pública federal, das autarquias, das fundações públicas, das empresas públicas e das sociedades de economia mista controladas pela União.

${ }^{3}$ A Lei $9.100 / 1995$ reserva ao menos $20 \%$ das vagas de cada partido ou coligação para candidaturas de mulheres.

${ }^{4}$ Regulamentação da conhecida Lei dos 2/3- Decreto 20.291, de 12 de agosto de 1931.
} 
No que se refere à reserva de vagas para educação escolar, Carvalho (2005, p. 3) chama a atenção para o Congresso do Negro Brasileiro de 1950, que ressaltou que a "(...) luta pelas ações afirmativas e as cotas nas universidades começou no Brasil no jornal Quilombo, que foi um jornal publicado em 1949 e 1950 pelo grupo de Abdias do Nascimento". No referido periódico já se defendia o que só veio a realizar-se no Brasil nos anos iniciais do século $X X I$, ou seja, que enquanto não se universalizasse a educação pública de boa qualidade aos brasileiros, capaz de garantir a igualdade de condições de acesso e permanência a todos, seria necessário que os estudantes negros fossem contemplados com a reserva de vagas.

No Brasil, o tema relacionado às cotas na educação começou a ganhar efetividade a partir dos anos 2000 em universidades públicas estaduais. Após constatarem a baixa presença ou mesmo a ausência de egressos de escolas públicas nos cursos, algumas universidades implementaram medidas com vistas à inclusão dos desfavorecidos.

As primeiras ações voltadas para a inclusão universitária ocorreram no Rio de Janeiro, com a aprovação da Lei Estadual № 3.524/2000, que estabelecia $50 \%$ das vagas do processo seletivo da Universidade do Estado do Rio de Janeiro (UERJ) e da Universidade Estadual do Norte Fluminense (UENF) para estudantes egressos de escolas públicas. Depois, segundo Passos (2014, p. 1096), “(...) em 2001, a Lei Estadual oㅜ 3.708/2001 [...] determinou a reserva de $40 \%$ do total destas vagas das duas universidades para quem se declarava negro ou pardo". Logo a seguir, as medidas adotadas nessas universidades foram aglutinadas e reconhecidas pela Lei Estadual oㅜ 4.151/2003.

As iniciativas da UERJ e UENF desencadearam outras semelhantes na Universidade do Estado da Bahia em 2002 e na Universidade de Brasília ${ }^{5}$ em 2004 , ao destinarem, respectivamente, $40 \%$ e $20 \%$ das vagas para candidatos que se declaravam negros.

Segundo Passos (2014, p. 1097), as

(...) tentativas de regulamentação - Projetos de Lei $\mathrm{n}$ o 73/19996, n. 3.198/2000 e n. $.^{\circ} 3.913 / 2008$, o estatuto da igualdade racial - foram apresentadas, objetivando instituir o sistema nas instituições federais de educação profissional, tecnológica e superior, mas todas foram arquivadas.

\footnotetext{
${ }^{5}$ Primeira universidade federal pública a adotar cotas raciais em seu processo seletivo.

${ }^{6}$ Primeiro projeto de lei (PL n. 73/1999) submetido ao Congresso Nacional que propôs a reserva de $50 \%$ das vagas das IES públicas para estudantes provenientes de escola pública. Autoria: deputada Nice Lobão.
} 
De acordo com Teles (apud CAMINO, 2014, p. 119), “(...) em 2002, algo próximo a 130 projetos de leis sobre questões raciais estavam para ser votados no Congresso Nacional".

Após anos de controvérsias, o Supremo Tribunal Federal (STF) decidiu sobre a constitucionalidade das cotas em 2012. Tal decisão abriu caminho para

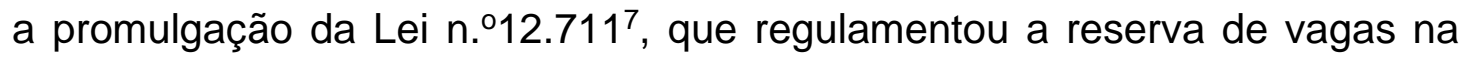
RFEPCT, não só para os cursos superiores como para os cursos da EPTNM. Aqueles que se mostravam contra as políticas afirmativas se depararam com 0 argumento irrepreensível apresentado por Mello (2012), em seu voto, no julgamento da "Arguição de Descumprimento de Preceito Fundamental186", que tratava da questão.

Quanto ao artigo 208, inciso V, há de ser interpretado de modo harmônico com os demais preceitos constitucionais. A cláusula "segundo a capacidade de cada um" somente pode fazer referência à igualdade plena, considerada a vida pregressa e as oportunidades que a sociedade ofereceu às pessoas. $A$ meritocracia sem "igualdade de pontos de partida" é apenas uma forma velada de aristocracia. (MELLO, 2012, p. 8).

Nos termos da Lei $n .012 .711 / 2012$, a reserva de vagas é equivalente à cota. As novidades foram as modificações nos processos seletivos utilizados pelas universidades, que tinham por base apenas as provas nos vestibulares.

A partir da publicação da Lei n. ${ }^{\circ} 12.711 / 2012$, a exigência é que o candidato à vaga tenha cursado integralmente a etapa anterior em escola pública. Ou seja, aos candidatos ao ensino técnico de nível médio é exigido que tenham cursado o ensino fundamental integralmente em escolas públicas, e aos candidatos ao ensino superior que tenham cursado integralmente $o$ ensino médio em escolas públicas.

\section{OS JOVENS COTISTAS DA EPTNM SUJEITOS DA PESQUISA}

Todos os jovens cotistas pesquisados tinham entre dezessete e dezenove anos; quatro eram mulheres e cinco eram homens e a maioria era originária de famílias pouco numerosas. Entre as nove famílias apenas três eram compostas por mais de quatro pessoas. No que se refere ao nível de escolaridade do casal de pais, constatou-se que em quatro casos ambos

\footnotetext{
${ }^{7}$ A lei dispõe sobre o ingresso nas universidades federais e nas instituições federais de ensino técnico de nível médio e dá outras providências.
} 
possuíam o mesmo nível de escolaridade; entre estes, um casal possuía formação de nível superior e os outros três, de nível médio. Entre os outros cinco casais, verificou-se que os pais não possuíam o mesmo nível de formação escolar e que o maior nível de escolaridade era o ensino médio. Entre esses pais apenas dois possuíam o ensino médio completo; dois, o ensino fundamental completo; cinco, o ensino fundamental incompleto, além de um caso de analfabetismo. Em síntese, os estudantes cotistas eram preponderantemente filhos de famílias com reduzida longevidade escolar.

Em associação às curtas trajetórias escolares dos pais, geralmente interrompidas por falta de oportunidades, gravidez não prevista ou necessidade de garantir a sobrevivência, verificou-se o ingresso precoce no mercado de trabalho, geralmente na informalidade ou em posições precárias na divisão técnica do trabalho. Entretanto, dessa reduzida longevidade na vida escolar e inserção precária e subalterna no mercado de trabalho, em boa parte tributária da baixa escolarização, não resultava por parte dos pais uma representação depreciativa da escola e seus saberes e nenhuma atitude indiferente em relação à permanência e ao sucesso escolar de seus filhos. A atitude desses pais em relação à escolarização dos filhos, segundo o relato de todos os estudantes entrevistados, era de incentivo e empenho. Todos os jovens reconheciam que muito do empenho de seus pais no trabalho visava a superar limites e favorecer suas vidas escolares na expectativa de ampliar e melhorar suas possibilidades de futuro.

Uma das consequências dessa atitude positiva dos pais é que a maioria dos jovens entrevistados também alegava acreditar na escola como plataforma para seus projetos de futuro. Muitos deles já tinham ouvido falar da unidade local da RFEPCT, e em cinco dos nove relatos verificou-se que irmãos e primos já haviam nela estudado. Os jovens informaram que a opção pelo ingresso na RFEPCT foi motivada pela reputação de melhor escola pública na cidade, pela oferta do ensino médio integrado e por terem sido incentivados por familiares, professores ou amigos.

Entre os objetivos citados pelos entrevistados consta a busca de uma sólida formação cultural, científica e técnica capaz de ampliar seus recursos tanto para o acesso ao ensino superior quanto para o ingresso no mercado de trabalho. A pesquisa não atentou para uma verificação da condição social e escolar dos avós e sua linha de ascendência. A despeito do observado é razoável supor que a condição dos pais dos cotistas era de certa ascensão em relação às suas origens e essa perspectiva era ainda mais nítida entre os filhos. Assim era a perspectiva que essas famílias traçavam nos três primeiros quinquênios do século XXI. Apesar das dificuldades, havia perspectivas de ascensão social e melhoria das condições e da qualidade da vida.

Verificou-se que todos os jovens, na intenção de garantirem a oportunidade, salvo uma exceção, buscaram ampliar suas chances de ingresso na RFEPCT com a realização de cursinhos preparatórios, frequentados após 
negociação de descontos e bolsas. No entanto, todos eles foram unânimes em afirmar que foi a política de reserva de vagas que tornou concreta a expectativa do acesso a esse novo campo de possibilidades e experiências.

Assim, a escola encaixou-se em seus projetos. Um meio para um fim ou "a oportunidade das oportunidades", como definido por um dos entrevistados. Dessa forma, quanto melhor a escola frequentada e quanto maior a sua legitimidade social, igualmente melhor e mais amplo seria o leque de possibilidades futuras e condições de progresso pessoal. As expectativas e atitudes dos estudantes cotistas eram direcionadas à conquista do que não tinham, mas gostariam de ter, e igualmente se desviar do que já fora experimentado como desagradável em seus passados, vivos em suas memórias. Memória essa que, segundo Velho (2003, p. 101), "(...) fornece os indicadores básicos de um passado que produziu as circunstâncias do presente, sem a consciência das quais seria impossível ter ou elaborar projetos.". E nesse sentido, cabe destacar que não são apenas experiências concretas ou elaboradas que mobilizam as ações, mas as expectativas de não repetir aquilo que já foi vivido. Os estudantes cotistas queriam mais, queriam ir além. Seus sonhos não se reduziam ao shopping center. Queriam estabilidade, previsibilidade, queriam ter família estruturada, queriam proporcionar melhores condições e margens de manobras para seus descendentes.

De acordo com relato dos entrevistados, a experiência vivida no ambiente da RFEPCT tornou-lhes possível um distanciamento de suas realidades. As novas experiências possibilitaram-Ihes condições para que pudessem avaliar, sob outra perspectiva, as próprias realidades em que viviam, como se conseguissem olhar de fora para a realidade em que se encontravam imersos. Esta síntese foi elaborada por uma das entrevistadas, ao afirmar que, apesar de não deixar de sonhar, se tornou "mais realista" e que agora enxergava um caminho mais real à frente. Tal passagem remete-nos novamente a Velho (2003) no tocante à relação entre projeto e fantasia. Também nos remete à experiência e expectativa nos termos sugeridos por Koselleck (2006, p. 312), quando afirma que "(...) quem acredita poder deduzir suas expectativas apenas da experiência, está errado. Mas quem não baseia suas expectativas na experiência também se equivoca. Estamos diante de uma aporia que só pode ser resolvida com o passar do tempo.".

A partir dos estranhamentos e dos "choques de realidade" narrados pelos estudantes, pode-se afirmar que a entrada na RFEPCT representou o acesso a um novo campo de possibilidades e de experiências, distintos daqueles até então vividos por eles. As novidades com as quais passaram a conviver e que impactaram as suas visões de mundo iam desde coisas aparentemente triviais, como a infraestrutura física da instituição, como o jardim bem cuidado, até os benefícios financeiros públicos para permanecer no curso. Entre os mais citados e significativos destacam-se o auxílio financeiro continuado recebido por meio da Assistência Estudantil, a liberdade escolar, a convivência com uma diversidade de ideias, estilos de vida e visões de mundo. 
Além destes, os jovens cotistas também citaram como impactantes, e não menos importantes, o acolhimento pela comunidade escolar, o ambiente isento de preconceitos e propício à manifestação do pensamento, o respeito às opiniões diferentes, os debates e diálogos, a disponibilidade dos professores fora dos horários de aula, as monitorias, a maturidade individual dos colegas e a aprendizagem solidária, a sensação de uma atmosfera típica da universidade, as atividades culturais e o direito à voz.

As questões acerca dos sujeitos beneficiados pelas políticas públicas de inclusão social, como as cotas, não raramente são tratadas com estereótipos e estigmas, nos quais o sujeito beneficiado é visto como desprovido de mérito, atitude e iniciativa. Este, pois, é um ponto que merece reflexão com base no que foi apurado.

Já foi mencionado que se trata de um público que atendia cumulativamente a todos os quesitos estabelecidos pela Lei $n .0$ 12.711/2012, mas é apropriado dedicar um tempo às suas histórias individuais e trajetórias escolares anteriores ao ingresso na RFEPCT. O objetivo aqui é dar relevo à aplainada concepção de cotista difundida, permitindo, assim, aos defensores extemporâneos da meritocracia e aos críticos das políticas de inclusão social, como as cotas na educação, outra perspectiva sobre a realidade dos sujeitos abrangidos por elas.

O jovem sujeito que chega à unidade escolar da RFEPCT traz consigo uma forma de viver (Ethos) e enxergar a realidade (Eîdos) como resultado da relação com seu espaço e tempo de vida, suas experiências e expectativas. Essa condição é equivalente a determinada capacidade de (res)significar aquilo que the acontece ou não acontece conforme lhes permitem os recursos objetivos e subjetivos (materiais e imateriais) de que dispõe. É portador de uma história própria. É feito e efeito das condições nas quais foi possível estar e ser.

Nos termos propostos por Koselleck (2006, p. 313), “(...) romper o horizonte de expectativa cria, pois, uma experiência nova". No mesmo sentido Velho (1999) salienta que novas experiências poderiam assim favorecer o surgimento de novas perspectivas e, por consequência, uma maior elaboração de projetos de futuro:

Quanto mais exposto estiver 0 ator a experiências diversificadas, quanto mais tiver de dar conta de ethos e visões de mundo contrastantes, quanto menos fechada for sua rede de relação ao nível do seu cotidiano, mais marcada será a sua autopercepção de individualidade singular. Por sua vez, a essa consciência da individualidade - fabricada dentro de uma experiência cultural específica - corresponderá uma maior elaboração de um projeto. (VELHO, 1999, p. 32). 
Nesse sentido, o raciocínio dos referidos autores estimula indagar se os jovens atendidos pelas políticas públicas, inseridos em novo espaço e campo de experiências e possibilidades, alteram suas perspectivas, seus horizontes de expectativas e, por consequência, seus projetos de futuro.

\section{A EXPERIÊNCIA DO ESTUDANTE COTISTA NA EPTNM DA REFEPCT}

No tocante ao espaço de experiências ou campo de possibilidades, temse "(...) a inarredável dimensão sociocultural, constitutiva de modelos, paradigmas e mapas" (VELHO, 2003, p. 8), em que se encontra o sujeito para elaboração de seus projetos. A noção de campo de possibilidades implica tanto no afastamento da ideia de um voluntarismo agonístico, em que se atribui apenas à vontade individual a responsabilidade pela transformação das suas condições de vida, quanto na objeção ao determinismo social, que em última instância desestimula quaisquer possibilidades de mobilidade social ao atrelar as possibilidades à estrutura social.

A maioria dos jovens entrevistados alegou acreditar na escola como base de sustentação e plataforma que antecede outras oportunidades para a elaboração e a realização de seus projetos de futuro. Eles informaram, como mencionado, que o empenho pelo ingresso na unidade da RFEPCT foi motivado pela reputação de melhor escola pública na cidade e pela oferta do ensino médio integrado.

Uma constante nos relatos dos jovens cotistas era a superação de adversidades e a busca por mobilidade social. Eram sujeitos que queriam sair da situação em que estavam e que encontraram na boa escola as condições para seguir em frente. Isso revela sintonia entre vontade e possibilidade, em que a boa escola pública proporciona possibilidades para efetivação das vontades. Os estudantes cotistas já chegam à RFEPCT com muitas vontades e expectativas. A instituição, por sua vez, oferece condições e possibilidades que, além de corresponder às expectativas trazidas pelos jovens, acabam ampliando-lhes simultaneamente horizontes e vontades, incentivando-os a novos projetos. Estar ali significava estar na melhor escola, em companhia dos melhores estudantes e isso produzia efeitos na autoestima e na autoconfiança, elementos decisivos na prospecção de futuros, na tomada de atitudes e na definição de posições. O resultado disso pode ser progresso.

Para alguns jovens cotistas entrevistados, a unidade da RFEPCT era como um "lugar mágico", de tão distinto dos seus lugares de origem. Para outros era como uma "bolha", uma "ilha", um lugar diferente em que as pessoas se preocupavam com o futuro; uma escola que, mesmo sendo de tempo integral e com menor tempo livre, Ihes possibilitou maior sensação de liberdade. Um ambiente de diversidade no qual as pessoas não apenas se respeitavam, mas afirmavam e compartilhavam suas diferenças. Um lugar no 
qual a convivência era tida como harmoniosa e isenta de preconceito e discriminação. Lugar de acolhimento e solidariedade, em que, a partir da escuta do outro, era possível rever atitudes pessoais, ampliar perspectivas, pensar de forma crítica, não apenas sobre questões sociais, mas, também, sobre si mesmos e seus modos de ser e estar no mundo. Nesse sentido não são irrelevantes os insights relatados pelos jovens sobre questões como a "autossabotagem" e o "medo de ter medo", a comparação desmedida com outras pessoas na igualmente desatinada crença de se estar em uma "corrida imaginária"; a autoexigência e a cobrança excessiva por resultados, geradora de ansiedade, estresse e adoecimento; a atitude introspectiva e a busca pelo jeito certo de respeitar as pessoas.

De início, como efeito da ação que os colocou no campo de possibilidade da RFEPCT, os jovens identificaram o próprio movimento para fora de seus bairros, situação que lhes exigiu, entre outros atos, deslocarem-se pela cidade, deixarem para trás a pequena escola do bairro e as amizades, para conviver com outras pessoas e experimentar outras rotinas.

Além da mudança de espaço, os jovens também alegaram realizar uma mudança significativa no tempo dedicado à escola. Saíram do tempo parcial para o tempo integral, passando a ficar o dia todo na escola. A maior permanência na escola possibilitou-Ihes a interação com pessoas de diferentes localidades, origens sociais, econômicas, com estilos de vida e visões de mundo diversas, com quem passaram a ter oportunidades de poder falar, de ser ouvidas e mesmo confrontadas em suas opiniões. No entanto, foi também essa condição que acabou favorecendo o surgimento de outras perspectivas, enriquecendo a experiência na constituição de suas identidades.

Foi muito explicitado pelos jovens que o acesso à RFEPCT era uma barreira considerável, principalmente diante da concorrência com os filhos das classes médias egressos de renomadas escolas particulares. Salientaram também que permanecer até o final do curso só foi possível graças ao auxílio financeiro continuado recebido por meio da Assistência Estudantil. Destaca-se que, entre os nove jovens entrevistados, sete receberam a assistência, descrita como essencial para cobrir custos com transporte, alimentação, uniformes, material escolar, internet e até mesmo para auxiliar nas despesas em casa. Foi consenso entre os assistidos a alegação de que sem esse apoio a permanência na RFEPCT seria muito difícil.

Outro ponto que merece saliência, tanto pela regularidade na fala dos jovens entrevistados, quanto pelos efeitos em suas subjetividades, tem a ver com a liberdade experimentada no ambiente escolar. É interessante notar a diferença que estabeleceram entre tempo livre e liberdade. Apesar de, durante o ensino fundamental, os entrevistados disporem de mais tempo livre, em razão de frequentarem a escola de tempo parcial, o ingresso no ensino médio em tempo integral foi relatado como uma experiência de maior liberdade. Tal situação faz pensar que dispor de mais tempo livre, mas sem oportunidades, 
não pode ser confundido com ter liberdade, pois esta, por sua vez, implica em possibilidades e condições de escolhas. Se não há condições para se exercerem escolhas, mesmo que o sujeito tenha mais tempo livre, a liberdade é prejudicada. Tal situação leva a concluir que possuiria menor liberdade aquele sujeito situado num campo de possibilidades mais restrito em oportunidades.

Muitos dos jovens entrevistados ficaram surpresos com essa nova condição de liberdade escolar. Não eram mais vigiados ou coagidos a fazer as coisas. Apesar de haver hierarquia, as relações estavam agora estranhamente mais horizontalizadas, não eram tratados como crianças, mas como sujeitos responsáveis por sua conduta escolar. Todos alegaram que os professores eram mais acessíveis, o que afetava positivamente o processo de aprendizagem, pois facilitava as interações. Além disso, os demais estudantes com quem se relacionavam estavam ali porque tinham um propósito, para o qual a dedicação aos estudos fazia sentido. Esta foi uma das vantagens alegadas de se estudar numa instituição verticalizada de ensino e com simultânea oferta de ensino médio e cursos superiores: o ambiente universitário.

Apesar dos embaraços com a tal liberdade no ambiente escolar, os estudantes cotistas relataram como positiva a experiência. Ressignificaram a primeira sensação de estar à própria sorte como uma estratégia formativa vinculada ao estímulo à independência, e avaliaram a falta de vigilância como parte de um processo que os tornou mais autônomos e responsáveis por aquilo que faziam. A experimentação da liberdade com oportunidades acabou colocando os jovens diante da questão sobre o que queriam para si, agora que não mais se sentiam coagidos ou controlados, o que, por sua vez, favoreceu o desenvolvimento da autonomia individual.

No tempo em que se discute a militarização da educação, na medida em que os colégios militares são citados como referência na formação do caráter por meio da disciplina, do rigor, da padronização e da uniformidade, percebese ao menos um contraponto diante das narrativas dos jovens entrevistados em condições de liberdade com oportunidade. A partir da experiência escolar dos jovens cotistas na EPTNM, com a abertura do campo da RFEPCT, também se verifica que, além do convívio com a diversidade, o respeito aos diferentes e a solidariedade, o exercício da liberdade como condição para saída da menoridade, tal qual posto por Kant (2010), o desenvolvimento da responsabilidade e a formação do caráter do sujeito são evidentes. Assim, pressupõe-se que se pode reconhecer sem maiores oposições, a partir das evidências expressas nas narrativas dos jovens, que a liberdade educa. Que a liberdade forma o caráter, forma valores, prepara o sujeito para a autonomia e para tomada de decisões. Que a liberdade vivida por eles os implicava eticamente no respeito à liberdade do outro. Que quanto maior o direito de liberdade do sujeito tanto mais ele teria a obrigação e o dever de respeitar a 
liberdade do outro. Nas narrativas dos estudantes entrevistados, a educação como prática de liberdade é, igualmente, educação para a responsabilidade.

Tal qual a surpresa e a aprendizagem na experiência com a liberdade, os estudantes destacaram também como relevante a convivência com a diversidade. Situações em que o respeito mútuo às diferenças e a solidariedade praticada entre os estudantes também educam para a cidadania, também produzem efeitos na formação integral da pessoa, bem como na promoção do bem-estar coletivo e na sustentabilidade das relações. Nesse sentido, ao se falar em sustentabilidade, pode-se pensar, em longo prazo, em valores estáveis no tempo, condição fundamental para se evitar a corrosão do caráter como sinalizado por Sennett (2001).

Outro ponto mencionado pelos entrevistados que merece destaque são seus relatos referentes a mudanças de mentalidades e no modo de ver 0 mundo, e de como estas transformações acabaram ecoando também fora da escola, em seus meios familiares e círculos sociais. Os jovens perceberam que se tornaram agentes de mudança em seus ambientes familiares. Além disso, sentiam que deixaram de ser tratados de modo infantil e a ter mais prestígio e influência, e, tal como ocorrido com eles, começaram a promover mudanças de perspectivas em seus familiares e amigos.

\section{MÉRITO E MERITOCARIA NA PERCEPÇÃO DO ESTUDANTE COTISTA}

Do ponto de vista dos jovens entrevistados, as condições financeiras familiares eram modestas e tudo muito bem calculado para não faltar nada. Todos eles relataram muito rigor por parte dos pais no controle dos gastos familiares. Apesar de não mencionarem situações de extrema carência, informaram que não dispunham de recursos para outras despesas relacionadas a bens de consumo ou lazer associados ao universo da infância e juventude, como brinquedos ou equipamentos eletrônicos. Conscientes de suas modestas condições de vida, mesmo diante de certas vontades pessoais, os jovens relataram que não pleiteavam nada além daquilo que estivesse dentro das possibilidades da família, que em boa parte já se encontrava comprometida com as despesas básicas. Em outros casos, diante da escassez, alegaram a prevalência de determinada conduta, em que aquilo que extrapolasse a satisfação das necessidades básicas era tido como um "luxo", por mais que estas se tratassem de itens indispensáveis como roupas, calçados e material escolar.

Em sintonia com a baixa renda das famílias, os jovens cotistas eram residentes em bairros periféricos e com carência de infraestrutura e serviços urbanos. Nesses locais, em que a ausência do Estado e a sensação de abandono se evidenciam na falta de segurança e lazer, outra lógica parece interferir na dinâmica das relações sociais. 
Já que nem mesmo na escola do bairro se sentia a garantia de proteção, distanciamento e interferência de uma "turma mais da pesada", e dada a impossibilidade de afastar-se de algumas situações, os estudantes cotistas relataram que tinham de desenvolver estratégias de convivência social. Como que se equilibrando num fio de navalha, um deles disse que precisava manterse com astúcia e flexibilidade a uma distância "dessa turma", distância que não fosse tão próxima a ponto de ser visto como um amigo, nem tão longe de modo a ser considerado um potencial inimigo.

Diante da escassez de condições básicas e oportunidades, é evidente o comprometimento da liberdade, que consequentemente tolhe as possibilidades de exercício da cidadania. Destaca-se ainda que, por causa da condição da baixa renda, constatou-se que quatro entre os nove jovens entrevistados realizavam, paralelamente aos estudos, trabalhos informais para complementar a renda familiar. $\mathrm{E}$ a razão para isto era auxiliar no custeio de suas despesas pessoais e domésticas, despesas que, segundo informaram, aumentaram depois que iniciaram seus estudos em tempo integral, numa escola fora do seu bairro.

Como não bastasse a insuficiência de recursos financeiros e da baixa formação escolar e qualificação profissional de seus pais, o que resultava em exaustivas jornadas de trabalho, vínculos informais, instáveis e precários e dos contextos sociais em que viviam, também se verificaram, nos relatos dos entrevistados, relações conturbadas em seus núcleos familiares, situações essas que demandavam deles capacidade emocional para lidarem, por exemplo, com alcoolismo, falecimento de progenitores, divórcio, desemprego, dependência química de familiares, tentativas de suicídio na família e prisões. Enfim, capacidade para lidarem com situações perturbadoras que concorriam com a sua dedicação integral aos estudos e a consequente permanência e sucesso na escola.

Tal constatação corrobora o que já apontara Dayrell (2016) no que tange à falta de moratória juvenil vivenciada por muitos dos jovens brasileiros com perfis semelhantes aos dos sujeitos desta pesquisa. Afinal, estes jovens precisavam superar dificuldades econômicas e desordens familiares que thes demandavam mais atenção e urgência do que a obrigação de se dedicarem plenamente à vida escolar. É nesse sentido que os jovens cotistas pesquisados eram mais expostos a efeitos nocivos em suas trajetórias e sofriam maiores restrições em suas margens de manobras, não apenas escolares, mas, também, sociais, diante dos reduzidos recursos que tinham para lidar com os problemas.

As biografias dos jovens entrevistados assemelhavam-se às de seus pais no que se refere às dificuldades para permanência na escola. Eles também alegaram defrontar-se com certas prioridades familiares, que, tensionadas pelas condições desfavoráveis, dificultavam a continuidade de seu desenvolvimento acadêmico. Como verificado nos relatos, os jovens passaram 
a infância e a adolescência entre uma família com problemas socioeconômicos, às vezes a rua e a escola. Considerados seus contextos de pobreza, é razoável afirmar que os jovens conviviam com adversidades que poderiam justificar dificuldades de adaptação na escola e para ser como um "aluno-problema", o que não veio a ocorrer. Pelo contrário, os jovens entrevistados informaram que sempre foram alunos estudiosos, empenhados, ocupando lugares de destaques entre os demais colegas de sala e da escola durante seu ensino fundamental. Bem antes de serem contemplados pela política de cotas nas escolas públicas, eles todos já eram possuidores de mérito escolar.

De modo geral, o sentido atribuído à escola tem sido relacionado à possibilidade de projetar-se no futuro alguma recompensa pelo esforço empreendido para frequentá-la no tempo presente. No entanto, com o futuro posto em xeque, assiste-se a um desencantamento com as instituições (DAYRELL, 2007), a uma crise de desinstitucionalização do social (PAIS, 2003), em que a escola como agência capaz de favorecer a mobilidade e a redução das desigualdades sociais pode perder legitimidade. Por outro lado, ganha predominância a perspectiva da ação do próprio sujeito sobre si para desenvolver-se. Apesar de importante para o desenvolvimento da autonomia, tal visão necessita ser considerada com cuidado para que não se sobrecarregue demasiadamente quem já não dispõe do necessário à sobrevivência.

Ainda nesse contexto de dificuldades e sacrifícios, os jovens entrevistados saíram em defesa das políticas públicas de reserva de vagas na educação como contraponto às disparidades sociais e como meio de se permitir que pessoas como eles tenham a chance de acessar novos campos de possibilidades, oportunidades e experiências que Ihes permitam ampliar seus horizontes de expectativas.

No entanto, apesar de reconhecerem a importância das políticas públicas relativas à reserva de vagas, sem as quais não teriam ingressado na escola da RFEPCT, os jovens entrevistados ressaltaram os seus esforços e sacrifícios, não apenas para conseguir entrar, mas, também, para permanecer na escola e concluir o curso. Embora, por um lado, eles demonstrassem compreensão em relação aos pais e a outros jovens com menores oportunidades, por outro destacaram a importância de suas proatividades na conquista das oportunidades, bem como a autoexigência quanto aos resultados a serem obtidos.

Talvez por essa razão eles fizessem questão de enfatizar que as oportunidades que tiveram foram conquistadas e vieram depois de muito esforço, iniciativa e persistência. Que nesse sentido, tais oportunidades resultaram de sua proatividade em buscar e criar as condições para superar as adversidades e acessar melhores possibilidades para o desenvolvimento de seus projetos. Os estudantes cotistas recusaram quaisquer possibilidades de 
ser acusados de oportunismo ou mesmo que fossem colocados em dúvida os seus méritos.

Eles e elas assim o fazem principalmente ao se considerar o discurso meritocrático propagado por quem não concorda com as políticas públicas de inclusão social, discurso esse defendido e difundido principalmente, segundo os entrevistados, por aqueles que já dispunham de privilégios e insistiam em confundir equidade com igualdade. Nesse sentido, salientou um dos entrevistados a insistência no discurso meritocrático, muitas vezes, intencionalmente mal-empregado, e sem levar em consideração outros fatores estruturais, que acabam por naturalizar uma concepção na qual se banaliza o sofrimento para justificar o acesso até mesmo a direitos fundamentais. Nessa mesma linha concluiu outro entrevistado que, por mais que as oportunidades de frequentar o mesmo espaço de experiências parecessem garantir a igualdade material entre as pessoas, ainda era preciso entender que persistiam outras condições (estruturais), tão impactantes quanto a falta de acesso a um mesmo campo de possibilidades. Embora não se recusassem a submeter-se a alguma dose de sacrifício para alcançar o que projetavam, os jovens apontaram que a disseminação extemporânea da ideia de meritocracia servia para justificar a manutenção de um sistema em que quem se beneficiava eram os que já possuíam as condições para sobressair-se nas situações de ampla concorrência, e não precisavam preocupar-se com questões básicas como as que eles tinham de enfrentar.

\section{PROJETOS DE FUTURO}

A partir de uma concepção de projeto de futuro referenciada em Velho (1999, 2003) e Koselleck (2006), pode-se afirmar que sua elaboração é resultado de uma complexa relação entre o indivíduo e seu campo de possibilidades, entre o sujeito e seu espaço de experiências, enquanto realidade compartilhada. Essa complexidade existe justamente por tratar-se de uma interação em que os elementos não são estáticos, mas, sim, dinâmicos e que podem transformar-se na própria interação. Nesse sentido, o projeto, sendo uma ação premeditada com vistas a uma finalidade, torna-se, conforme Velho (2003, p. 103),

(...) o instrumento básico de negociação da realidade com outros atores, individuais ou coletivos. Assim ele existe, fundamentalmente, como meio de comunicação, como maneira de expressar, articular interesses, objetivos, sentimentos, aspirações para o mundo. 
Assim, de volta às alegações apresentadas pelos estudantes entrevistados, verifica-se que, apesar de se constatarem, em pelo menos dois casos, resistências dos pais em relação às escolhas dos filhos, não houve registros de imposições aos jovens quanto às decisões e opções profissionais. $\mathrm{Na}$ verdade, os jovens demonstraram que tinham conseguido dialogar com seus pais e obtido êxitos em suas escolhas e na definição de seus projetos de futuro. Isso é relevante na ideia de projeto apresentada por Velho (1999, p. 24) em que: "(...) a noção de que os indivíduos escolhem ou podem escolher é a base, o ponto de partida para se pensar em projeto". Ainda que tenham conseguido assegurar suas escolhas, cabe destacar que tal negociação com a família foi um fator interveniente na elaboração dos projetos pelos jovens. Algumas narrativas ilustram bem a proposição de Koselleck (2006) no que se refere às relações entre experiência e expectativa. Considera-se que os pais, pela existência temporal de suas vidas, representam a tradição e portanto teriam mais experiências que expectativas; os filhos, por sua vez, dispõem de menos experiências e mais expectativas. Nesse encontro geracional é comum a tensão entre passado e futuro, experiências e expectativas, situação que requer constante negociação para se alcançar o equilíbrio e se evitarem o predomínio de uma posição sobre a outra e efeitos adversos (prejudiciais) sobre os arcos temporais lançados do presente para o futuro.

Nesse sentido é interessante notar que entre os jovens entrevistados havia plena variedade de opções profissionais, fato que faz pensar no grau de desenvolvimento da individualidade, independência e autonomia deles para fazerem escolhas. Demonstraram que não se restringiam às diretivas mercadológicas ou familiares. Queriam antes se dedicar àquilo com que se identificavam e que prometia satisfação pessoal. Entre as perspectivas profissionais estavam: administração pública, magistério, advocacia, medicina, jornalismo, engenharia, fisioterapia ou educação física, computação, música e empreendedorismo. Destaca-se como motivações para essas escolhas profissionais a alegada questão de poderem trabalhar com aquilo de que gostavam e que podia gerar realização pessoal. Para os jovens entrevistados o retorno financeiro mostrou-se como um objetivo menos decisivo do que a busca de satisfação pessoal. Eles alegaram acreditar que o retorno financeiro seria uma consequência de um trabalho bem feito e que aquele que faz o de que gosta se torna mais eficiente no que faz. Nesse sentido não hesitaram em apostar em profissões menos tradicionais, como numa narrativa de um dos entrevistados, ao dizer de seu interesse em fazer da música seu horizonte profissional: a música é também uma alternativa de renda. Comumente se associa a música à arte, mas ela pode ser trabalho e fonte de renda.

Os jovens entrevistados disseram priorizar a satisfação pessoal ao sucesso financeiro, o bem-estar e a saúde física e mental ao status profissional. Não desconsideram a importância do retorno financeiro como meio para uma vida menos estressante e mais estável para a constituição de uma família estruturada, e para conseguir melhores condições de conforto e lazer. Por outro 
lado, não queriam viver ou sacrificar a saúde e suas relações sociais em função do dinheiro. No entanto, ao longo dos relatos, notou-se que parecia haver certo pudor ou desconforto em torno da questão relacionada ao dinheiro, em que se entrelaçava de forma complexa: aquilo que não se tinha, nem se fazia tanta questão de possuir, mas de que precisavam e não podiam abrir mão. Assim, enquanto na escola se esforçavam às vezes mais do que se era pedido para obter reconhecimento, boas notas e destaque individual, no campo profissional, quando se tratava do retorno financeiro, parecia haver algum tipo de conflito ou embaraço. Tal constatação sugere um ponto a ser abordado oportunamente pelas escolas - a educação financeira.

Ainda no que se refere às pretensões financeiras, os jovens disseram que não queriam ser ricos, mas almejavam ter o suficiente para poder viver sem maiores preocupações e sacrifícios. Queriam "(...) sair da classe C do Brasil e ascender futuramente para a classe média. Ter um tipo de vida estável", afirmou um deles; "(...) ter uma vida financeira melhor, para criar uma família mais estruturada. Poder ter mais chance de lazer, poder viajar, poder conhecer mais lugares, poder ajudar o outro", destacou outro. Aliás, viajar foi, se não a mais, pelo menos uma das mais citadas expectativas dos entrevistados. Viajar para conhecer lugares diferentes parece representar bem um dos objetivos dos jovens por mobilidade, para sair de onde se encontravam e buscar outras experiências e novos horizontes.

Outra regularidade presente na maioria dos relatos, além de progredir na vida, ter acesso a bens materiais de consumo, ter conforto etc., era o de poder ajudar outras pessoas. Os jovens entrevistados colocaram a solidariedade em seus horizontes de pessoas bem-sucedidas. Isso remete à Sennett (2001) e faz pensar na integridade do caráter dos jovens. Se se entende que o desenvolvimento do caráter depende de virtudes estáveis, como lealdade, confiança, comprometimento e solidariedade, percebe-se que mesmo diante da incerteza do futuro aberto, em que a instabilidade sintetizada na expressão "não há longo prazo", os jovens demonstraram que não estavam à deriva. Pelo contrário, ao revelarem em seus projetos a presença de valores estáveis, parece incontroverso concluir que os jovens não demonstraram o caráter corroído pelas efemeridades e incertezas do tempo presente.

A partir da análise das narrativas dos jovens foi possível identificar que a maioria deles, ao apresentar-se à EPTNM da RFEPCT, já trazia expectativas de um futuro diferente daquele condicionado pelo seu lugar na estrutura de uma sociedade desigual e excludente, e que tais expectativas tinham na boa escola uma referência para a mobilidade. Foi também possível perceber que os jovens pretendiam alcançar e promover melhores condições para si, seus familiares e respectivos descendentes no futuro. Tal situação guarda correlação com o exposto por Velho (2003), ao mencionar que a consistência de um projeto estaria justamente em sua capacidade de compreender as circunstâncias do presente sob a perspectiva do passado que o produziu. Conforme Velho (2003, p. 101), “(...) se a memória permite uma visão 
retrospectiva mais ou menos organizada de uma trajetória e biografia, o projeto é a antecipação no futuro dessa trajetória e biografia.".

Se o projeto é compreendido como uma conduta organizada para atingir finalidades específicas, logo são elas - as finalidades - que se tornam o combustível para a ação no presente. Todavia, na composição de tais finalidades, encontra-se também certo interesse em afastar-se do passado e evitar que ele se repita no futuro. Algo que, por sua vez, sob a perspectiva do olhar do passado, pode apresentar-se inatingível ou mesmo incerto. A propósito, essa parece ser a condição para um futuro aberto: a incerteza. Nesse sentido as finalidades objetivas ou aquelas expressas em expectativas tornam-se elementos capazes de colocar em movimento as ações no presente voltadas para o futuro, justamente porque este pode ser visto, ainda que por um instante, com novas possibilidades.

Assim, tanto as experiências passadas quanto as expectativas como forças motrizes servem de impulso para a realização de ações no presente. Isso demonstra, em certo sentido, que uma ação com finalidade específica empreendida no presente é tanto mobilizada pelas experiências concretas de um passado (gravadas na memória), quanto pelas expectativas de se conquistar nova condição no tempo futuro. Além disso, e atreladas às experiências e expectativas, ainda se acrescentam as condições expressas pelo campo de possibilidades tido como a "(...) dimensão sociocultural, espaço para formulação e implementação de projetos” (VELHO, 2003, p. 40).

Nesse aspecto é possível destacar algumas das mais frequentes finalidades reveladas pelos jovens, ainda que expressas em expectativas, que, além de orientarem suas ações no presente, revelam de certa maneira aquilo que esteve ausente em seus passados. Algo muitas vezes evidenciado pela ideia de "dar o que não se teve", manifesto de modo literal em algumas narrativas. Portanto, considerando que as expectativas, assim como as finalidades específicas, colocam em movimento os projetos, destacam-se nos relatos dos jovens o interesse pela formação em nível superior, a construção de uma carreira profissional, boa colocação no mercado de trabalho, boa remuneração, condições familiares estáveis, boa qualidade de vida, atividades profissionais menos estressantes, melhores chances de lazer e viagens e solidariedade com outras pessoas. A declaração de um dos entrevistados sintetiza a trajetória futura idealizada pela maioria dos jovens:

Acho que o caminho que eu estou seguindo, estudando aqui, com o ensino médio mais puxado, mas que te prepara para o Enem, acaba acarretando melhor uma chance de você entrar em uma faculdade... no final você arranja um emprego que pode te dar oportunidade de ajudar a família, quando você conseguir condições financeiras estáveis. (MILTON, 18 anos.) 
O acesso e permanência na EPTNM da RFEPCT foram apontados pelos jovens entrevistados como uma etapa significativa na estratégia de alargamento de seus campos de possibilidades e horizontes de expectativas. A alegação era de que o ensino médio integrado thes asseguraria uma formação técnica capaz de proporcionar recursos e alternativas para lidarem com eventuais percalços em seus projetos de obter a formação em nível superior, necessária para garantir a mobilidade projetada. Portanto, o interesse em continuar a formação escolar em nível superior guarda relação com a expectativa de melhores colocações no mercado de trabalho, em profissões reconhecidas e valorizadas dentro da divisão social e técnica do trabalho e, com efeito, por condições mais estáveis de vida.

Embora a maioria dos jovens entrevistados visasse ao ingresso no ensino superior, não desconsiderava a formação técnica como um valor em seus currículos e como um recurso que poderia ser usado se as circunstâncias assim o exigirem. Dois entre os nove estudantes cotistas alegaram falta de interesse pela formação técnica, outros dois não se identificaram com os cursos realizados e cinco afirmaram que se identificaram com os cursos, aprenderam a técnica e estavam aptos ao exercício profissional, a despeito de priorizar o curso superior. Quanto à formação geral, todos os entrevistados consideraram que haviam progredido e que era bem menor a distância que sentiam em relação aos seus pares no primeiro ano de sua presença na RFEPCT. Os jovens alegaram sensação de autoconfiança e otimismo quanto às possibilidades de ingresso no ensino superior em reconhecidas universidades públicas.

\section{CONSIDERAÇÕES FINAIS}

A recente normatização pelo Estado brasileiro e as repercussões que a questão das cotas escolares têm tido reforçam a importância de estudos sobre a temática da inclusão social, bem como os efeitos das políticas públicas de inclusão social. É nessa perspectiva que se optou por abordar o projeto de futuro dos jovens atendidos pela política de cotas. Entre os motivos para se pesquisar esse assunto destaca-se o interesse em contribuir para o avanço no desenvolvimento de propostas e estratégias institucionais de acolhimento, apoio e orientação de jovens na elaboração de seus projetos de futuro (pessoal e profissional), de modo a equalizar recursos, expectativas e possibilidades concretas dos atores envolvidos.

Feito o percurso, considera-se que a investigação conseguiu identificar a relação entre as possibilidades e experiências propiciadas pela RFEPCT e os projetos de futuro dos jovens. Verificou-se que, mesmo que a escolarização em si não seja garantia de concretização de expectativas, ela tem sido considerada pelos estudantes cotistas como possibilidade para outras oportunidades e por esta razão fonte de investimentos pessoais. 
Verificou-se também que a formação escolar pública, gratuita e de boa qualidade se encontra entre as etapas a serem realizadas dentro da estratégia dos jovens para melhorarem suas vidas no futuro. Seja para garantir a formação profissional exigida para o mercado de trabalho, seja para o ingresso no ensino superior em universidades públicas, seja ainda para adquirir conhecimentos gerais para leitura de mundo, a formação escolar encontra-se, na concepção dos estudantes cotistas, como caminho para a mobilidade social.

Além disso, a experiência na EPTNM da RFEPCT mostrou-se capaz de estimular mudanças nas perspectivas e na autonomia dos jovens cotistas, mudanças suficientes que lhes permitam repensarem e refazerem a própria autoimagem e autoestima, modificarem seu modo de ver, viver e agir no mundo e superarem alguns limites postos pelas circunstâncias socioeconômicas e culturais. Como exemplo pode-se citar o interesse por assuntos relativos à cultura e à política. Registra-se que as mudanças vividas pelos sujeitos cotistas foram estendidas aos seus ambientes familiares e de amizade, tornando-os agentes (vetor) de estímulo para transformações pessoais e sociais.

Tal constatação confirma que o espaço de experiências da EPTNM da RFEPCT proporcionou aprendizagens significativas e transversais, situadas muito além dos currículos prescritos e escritos, muito além da sala de aula. Nesse sentido vê-se realizado aquilo que se persegue nos projetos políticopedagógicos de instituições educativas de boa qualidade, a saber: possibilitar ao sujeito que nela se inicia tornar-se, a cada nova etapa do percurso, capaz de ir além do que the foi ensinado e tornar-se produtor de produzir novos saberes e competências para dirigir-se nas situações da vida cotidiana.

Apesar de a pesquisa não ter explicitado hipóteses, havia certa expectativa de que os estudantes cotistas pudessem não ter projetos de futuro antes de ingressar na RFEPCT, e que, a partir do acesso a esse novo campo de possibilidade, viessem a tecer projetos para o futuro. Nesse cenário, a experiência na RFEPCT seria como um divisor de águas. A pesquisa não confirmou essa expectativa, apesar de se encontrar um caso correspondente a tal prognóstico. Todavia, embora a maioria dos jovens já tivesse perspectivas pessoais de longevidade escolar e de ascensão social, eles alegaram que se tornaram mais realistas, consolidaram as suas escolhas profissionais e se tornaram mais confiantes a partir de seu percurso na RFEPCT. Ou seja, os sujeitos cotistas (pobres, da periferia, oriundos da escola pública) já tinham trajetória escolar de destaque bem como projetos para o seu futuro. A novidade é que a RFEPCT, como campo de experiências e de possibilidades, tanto abriu novos horizontes de expectativa quanto deu substância e forças para os projetos de futuro.

Outro ponto relacionado ao campo de possibilidades é a oportunidade de alteridade no ambiente da RFEPCT, marcada pela convivência com pessoas de diferentes origens sociais e geográficas, com realidades, estilos e visões de mundos distintos daquela dos estudantes cotistas. Nesse sentido, a 
unidade da RFEPCT foi reconhecida pelos jovens cotistas como um centro aglutinador de diferenças, um lugar de diversidade, um lugar no qual se encontram sujeitos de diferentes origens sociais: gente do centro e da periferia, gente de classe média e gente pobre, gente branca, gente parda e gente preta.

Mesmo em condições adversas, os jovens alegaram-se otimistas quanto ao futuro. As incertezas e inseguranças existem, mas não são maiores que a esperança elaborada. Mesmo não tendo à disposição maiores margens de segurança para lidar com eventuais contratempos, os jovens disseram-se dispostos a enfrentar e superar dificuldades e obstáculos. Seus projetos mostram-se em boa medida compatíveis com as possibilidades a seu alcance.

A expectativa de novos horizontes mostra-se como um elemento importante para a estabilidade das relações entre o sujeito e a sociedade no tempo presente. Tal mecanismo encontra-se na base, não apenas dos processos modernos de socialização (LECCARDI, 2006), mas na base dos processos civilizatórios (FREUD, 1996c). Assim, a falta de perspectiva e horizonte parece tão nociva quanto a perspectiva de cenários desoladores ou obscuros, pois resulta num presente desnorteado ou como situação de deriva.

Sem a ideia de longo prazo, os sujeitos tendem a lançar arcos temporais relativos ao futuro cada vez mais curtos, resultando em laços sociais menos duradouros e consistentes, aumentando a sensação de desamparo e pondo em risco a integridade do caráter, que depende de referências estáveis. Afinal, atitudes com referência no longo prazo em relação ao tempo futuro são indicativas de condições para a edificação do caráter (SENNETT, 2001). De outra forma, a falta de perspectiva em longo prazo é algo que contribui para a corrosão do caráter, pois este depende de virtudes estáveis como lealdade, confiança e comprometimento, que, por sua vez, requerem longa duração. Portanto, ações que possibilitem a abertura de novas experiências com potencial para promover perspectivas de futuro são importantes não só para o sujeito em particular, mas para um país que também precisa ter para si um projeto de futuro.

Entre as conclusões deste estudo constam que os novos jovens ingressantes por meio das cotas à RFEPCT são possuidores de mérito, e que a escola pública do ensino fundamental, pelas mais diversas razões, se tem mostrado aquém de suas capacidades de desenvolvimento e interesses. Mesmo inseridos em ambientes e condições socioeconômicas desfavoráveis, os jovens atendidos pelas cotas reconhecem a escola e a boa educação como oportunidade para outras oportunidades.

Por mais que as cotas sejam uma medida paliativa, revelam-se, diante da incapacidade de se garantir a universalização do acesso à educação básica de boa qualidade, algo capaz de proporcionar a seus egressos condições de concorrerem por outros espaços e campos com maiores possibilidades. Assim sendo, as ações que atuam no sentido de ampliar o horizonte dos jovens 
apresentam-se como medidas essenciais ao desenvolvimento, entre outros, do caráter, do pensamento crítico e do pleno exercício da cidadania.

\section{REFERÊNCIAS}

BAYMA, Fátima. Reflexões sobre a constitucionalidade das cotas raciais em universidades públicas no Brasil: referências internacionais e os desafios pósjulgamento das cotas. Ensaio: avaliação e políticas públicas em educação, Rio de Janeiro, v.20, n.75, p.325-346, jun. 2012.

BRASIL. Lei n. .012 .711 , de 29 de agosto de 2012.Dispõe sobre o ingresso nas universidades federais e nas instituições federais de ensino técnico de nível médio e dá outras providências. Diário Oficial da União, Brasília, Seção 1, p. 1, 30 ago. 2012.

CAMINO, L.; TAVARES, T. L.; TORRES, A. R. R.; ÁLVARO, J. L.; GARRIDO, A. (2014). Repertórios discursivos de estudantes universitários sobre cotas raciais nas universidades públicas brasileiras. Psicologia \& Sociedade, 26 (n. spe.), p. 117-128, 2014.

CARVALHO, José Jorge de. Inclusão étnica e racial no ensino superior: um desafio para as universidades brasileiras. Brasília: Departamento de Antropologia, Universidade de Brasília, 2005.

CARVALHO, José Jorge de. A política de cotas no ensino superior: ensaio descritivo e analítico do mapa das ações afirmativas no Brasil. Brasília: INCT, 2016.

DAYRELL, Juarez. A escola "faz" as juventudes? Reflexões em torno da socialização juvenil. Educação \& Sociedade, Campinas, v. 28, n. 100, out. 2007.

DAYRELL, Juarez Tarcísio; JESUS, Rodrigo Ednilson de. Juventude, ensino médio e os processos de exclusão escolar. Educação \& Sociedade, Campinas, v. 37, n. 135, p. 407-423, maio/jun. 2016.

FREUD. Sigmund. (1929). O mal-estar na civilização. Edição Standard Brasileira das Obras Completas de Sigmund Freud, v. XXI. Rio de Janeiro: Imago, 1996c.

KANT, Imannuel. O que é o esclarecimento? In: Imannuel Kant. Textos seletos. Tradução de Floriano de Souza Fernandes. 4. ed. Petrópolis: Vozes, 2010.

KOSELLECK, Reinhardt. Futuro passado: contribuição à semântica dos tempos históricos. Rio de Janeiro: Contraponto; PUC Rio, 2006.

LECCARDI, Carmen. Para um novo significado do futuro: mudança social, jovens e tempo. Tempo Social, São Paulo, v. 17, n. 2, p. 35-57, nov. 2005.

MELLO, M. A. Íntegra do voto do ministro Marco Aurélio Mello na ADPF sobre cotas. Brasília, DF: STF, 2012. Disponível 
em:<http://acoesafirmativas.ufsc.br/files/2013/03/ADPF186MMA.pdf>. Acesso em: 12 nov. 2017.

PAIS, J. M. Ganchos, tachos e biscates: jovens, trabalho e futuro. Lisboa: Âmbar, 2003.

PASSOS, Guiomar de Oliveira; GOMES, Marcelo Batista. A instituição da reserva de vagas na universidade pública brasileira: os meandros da formulação de uma política. Ensaio: avaliação e políticas públicas em educação, Rio de Janeiro, v. 22, n. 85, p. 1.091-1.114, 2014.

SENNETT, Richard. A corrosão do caráter: consequências pessoais do trabalho no novo capitalismo. Rio de Janeiro: Record, 2001.

VELHO, G. Individualismo e cultura: notas para uma antropologia da sociedade contemporânea. Rio de Janeiro: Jorge Zahar, 1999.

VELHO, G. Projeto e metamorfose: antropologia das sociedades complexas. 3. ed. Rio de Janeiro: Jorge Zahar. 2003. 